\section{A simple technique for obtaining prometaphase chromosomes from lymphocytes}

The human chromosomes of 'prophases' and 'prometaphases' reveal more bands that can be seen even in the best banded 'metaphase' chromosome. The earlier techniques in obtaining prometaphase chromosomes are rather complex ${ }^{1}$ and require several steps. This report describes a simple method for synchronising peripheral blood culture and obtaining sufficient cells at the appropriate stage of division for high resolution banding.

Lymphocytes from peripheral blood from normal donors (10 females and 10 males) were cultured for 68 to 72 hours at $37^{\circ} \mathrm{C}$ in $5 \mathrm{ml}$ of $1 \mathrm{~A}$ medium (Cat No 120-1670 Grand Island Biological) supplemented with fetal calf serum and phytohaemagglutinin. After 68 to 72 hours' incubation, the cultures were treated with 5-bromo-2-deoxyuridine (200 $\mu \mathrm{g} / \mathrm{ml}$, Sigma) and $0.3 \mu \mathrm{g} / \mathrm{ml}$ of thymidine (Sigma) for exactly $4 \frac{1}{2}$ hours. Before harvest, cultures were treated for an additional half hour with colcemid $(0.03 \mu \mathrm{g} / \mathrm{ml}$, Gibco Diagnostic). It is important to mention that BrdU and thymidine are added at the

Received for publication 11 June 1983.

Accepted for publication 26 June 1983. same time and no washing is required. Colcemid was also added without removing the other two chemicals. The cells were then harvested by the standard techniques. GTG banding ${ }^{2}$ was performed immediately after harvest and good quality bands were obtained. For RFA banding ${ }^{3}$ slides were allowed to age for 7 to 10 days. In the figure, chromosome 1 is shown as an example of GTG and RFA banding. The diagrammatic pattern is reproduced from the recent nomenclature on high resolution banding. ${ }^{4}$

Several concentrations of BrdU and thymidine with variable durations of treatment were tried. A brief exposure of $4 \frac{1}{2}$ hours to BrdU $(200 \mu \mathrm{g} / \mathrm{ml})$ and thymidine $(0.03 \mu \mathrm{g} / \mathrm{ml})$ produced the best results. By this method it is possible to obtain prophase or prometaphase spreads suitable for $G$ banding within 75 hours. Reduction in exposure time to BrdU produces more mitoses. A lower concentration of colcemid $(0.03 \mu \mathrm{g} / \mathrm{ml})$ is also an important factor in obtaining good preparations. This improved technique is a valuable tool in the analysis of prometaphase chromosomes.

J V ShaH, R S Verma, J Rodriguez, AND H Dosik Departments of Laboratories and Medicine, The Jewish Hospital and Medical Center of Brooklyn and SUNY Downstate Medical Center, Brooklyn, NY 11238, USA.

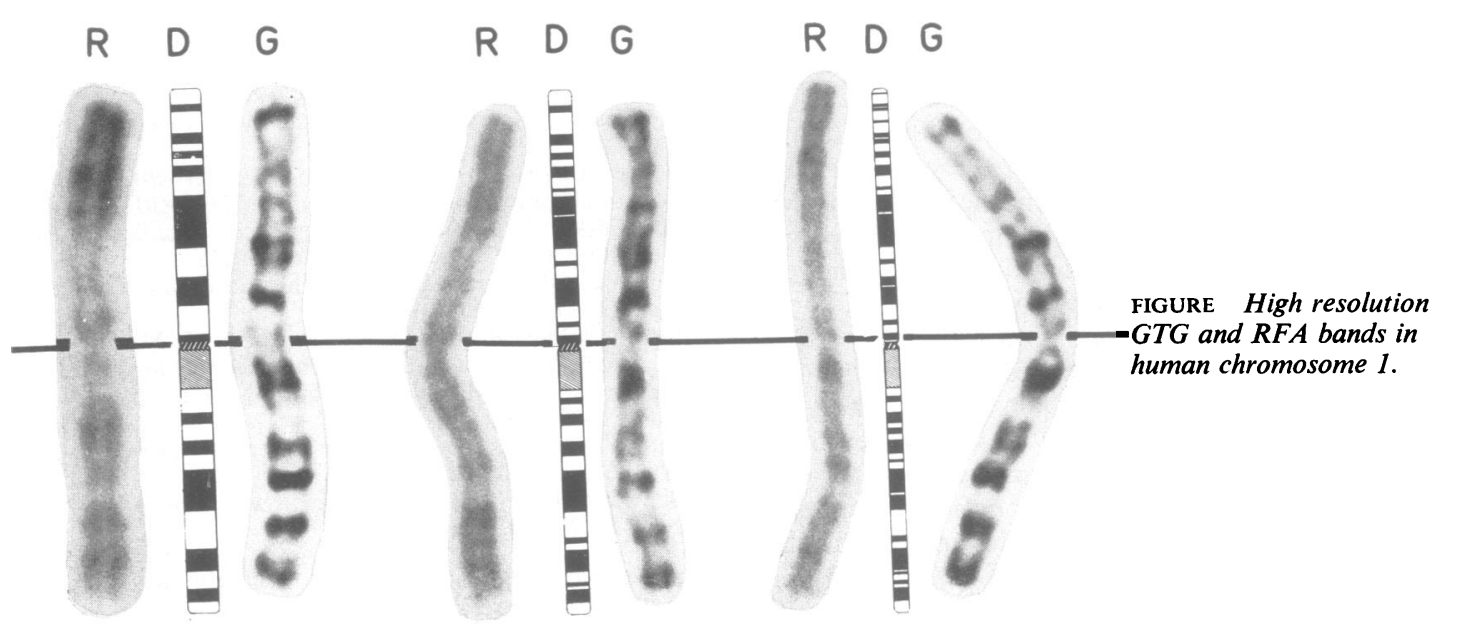




\section{References}

1 Yunis JJ. Mid-prophase human chromosomes. The attainment of 2000 bands. Hum Genet 1981 ;56:293-8.

2 Seabright M. A rapid banding technique for human chromosomes. Lancet 1971 ;ii:971-2.

3 Verma RS, Dosik H. An improved method for photographing fluorescent human chromosomes $J$ Microsc 1976;108:339-41.
4 ISCN (1981). An international system for human cytogenetic nomenclature. High resolution banding. Birth Defects 1981 ;XVII : No 5.

Correspondence and requests for reprints to $\mathrm{Dr}$ Ram S Verma, Division of Cytogenetics, The Jewish Hospital and Medical Center, 555 Prospect Place, Brooklyn, NY 11238, USA. 